\title{
Experimental Investigation on Thermal Properties of Wood-Plastic Composites as Flat Panels
}

\author{
Hadeel Mahmood Mussa, Tawfeeq Wasmi M. Salih *
}

College of Engineering, Mustansiriyah University, Iraq.

*Email: hadeelmussa52@gmail.com; Corresponding Author.

\begin{abstract}
The aim of this research is investigating the thermal properties of wood-plastic composites (WPCs) in the form of flat panels. The study has included many properties such as: thermal conductivity, thermal stability, thermal expansion and melting point. The WPCs have made of high-density polyethylene (HDPE) and polypropylene (PP) incorporated with wood flour taken from pine trees. The studied concentrations of wood flour in the composites are $(10,20$ or 30 $\%)$. The work was performed experimentally by manufacturing the specimens and measuring the thermal properties. The results show that the addition of $10 \%$ wood flour to the composite, leads to a reduction in the thermal conductivity of $4-10 \%$, a reduction in thermal expansion of $8-12 \%$, and an increase in the melting point of $\left(2-3^{\circ} \mathrm{C}\right)$ for both HDPE and PP wood composites. It was found that wood could be used with plastics that have low melting points, such as: HDPE, LDPE, PP, PVDF and PA, to ensure high thermal stability.
\end{abstract}

Keywords: thermal properties; wood, plastic; composites; panels.

\section{INTRODUCTION}

Recently, many investigations have been developed to invest the recycled materials for many applications such as supporting, decorating, waterproofing, soundproofing and thermal insulating. Plastic has a negative impact on the environment and consumes extra sources of raw materials, but it has many advantages like lightweight, flexibility and durability. Plastic waste control is a fundamental part in the development of solid waste management. For example, the 
adoption of the proposed sustainable drinking water solution led to $90 \%$ reduction in plastic pet bottle waste (Saleem et al., 2019). Wood plastic composites (WPCs) are relatively new family of composites and environmentally friend materials, where they can be manufactured from recycled plastics and waste woods. The wooden materials are usually: wood fiber, flour fiber, kenaf hemp and sisal. While, the plastics are usually: polyethylene (PE), polypropylene (PP), polyvinyl chloride (PVC) (Tabarsa et al., 2011). Wood contents in WPCs may reach 50\% of the composition. The wood and thermoplastics are usually compounded above the melting temperature of the thermoplastic polymers and then further processed to make various products. WPC can be manufactured in a variety of shapes and sizes, and with different surface textures depending on the processing method (Adam et al., 2010). Factors attributes to mechanical and thermal properties of WPCs depend on (Andre, 2011): wood content, type of polymer, type of additives and processing temperature. Studies conducted in PWCs show that the presence of wood contents increases the thermal properties, i.e. thermal resistance (João et al., 2017). On the other hand, the mechanical properties, i.e. tensile strengths, decrease with the increasing of wood fibers for a certain range (Wolcott et al., 1999). Researchers have been looking for the development of plastics with natural wooden materials as reinforcement. In this context, wood is usually used as flour or fiber in the composition of composite material. Several promising studies (John et al., 2004 - Xingly et al., 2019) have taken place in the evaluation of thermal properties of wood plastic composites (WPCs), for several wood types, wood contents, and polymer types as well as additives contents. Most of the studies were experimental investigations, while some others were theoretical and numerical studies or models. For example; (John et al., 2004) have studied thermal and mechanical properties of selected wood-PVC composites. (Alireza, 2010) has studied the effects of wood contents on the thermal properties of wood-HDPE-MAPP composites for high wood contents (about 60\%). Song et al., 2010) have used waste cartons instead of normal wood fiber to manufacture the WPC. Also, (Diene et al., 2011) studied the thermal behavior of crystallization temperature (Tc) and melting temperature (Tm) due to wood adding. Moreover, (Thanate et al., 2012) studied the thermal stability of WPC made of HDPE and oil palm wood sawdust (OWS). 
Furthermore, (Xingly et al., 2019) studied the influences of thermal filler content and temperature on the thermal performance of the modified WPCs with Graphene.

However, the major outcome of the previous works had focused on some thermal parameters like the thermal stability of WPC material or the variation in phase change zone and the corresponding melting point, temperature of crystallization and glass transition temperature. Less concentration had taken place for the effect of wood content on the thermal conductivity. Hence, the present study focuses on the thermal conductivity as a preferable parameter in the performance. The present study suggested WPCs made of two types of thermoplastics, high density polyethylene (HDPE) or polypropylene (PP) combined with pine wood floors in different concentrations $(10,20$ or $30 \%)$.

\section{MATERIALS AND METHODS}

In the current study, wood-plastic composites (WPCs) have made of recycled woods and plastics and proposed as thermal insulation panels. Experimental work has been done to manufacture and evaluate the thermal behavior of WPCs. The work includes manufacturing a set of specimens with different wood concentrations. The tests include measuring: thermal conductivity, melting point and thermal stability for the suggested WPC specimens. Natural pine wood (PW) has been collected from the local market and processed to become sawdust, then dried and grinded in order to obtain pure wood flour. Initially, a solid sample of the wood had taken to calculate the density using the mass-dimension method, which is commonly known by measuring both: mass and volume. The density $\left(0.41 \mathrm{~g} / \mathrm{cm}^{3}\right)$ and thermal conductivity $(0.12 \mathrm{~W} / \mathrm{m} . \mathrm{K})$ have been compared with average values that taken from reliable sources (Henry 2010, Glass 2010, Poletto 2010, Poletto 2016). There is a slight percentage of variation (less than 10\%) and that is almost due to the difference in the feature of wood. Thermoplastics that have melting point less than wood degradation temperature are commonly used with WPCs. Two types of thermoplastic materials have been purchased from the local market, which are: High Density Polyethylene (HDPE) and Polypropylene (PP). Average values of some properties of these plastics are shown in Table 1 (Polymer Database, 2020). 
Table 1. Some properties of plastics used in the study

\begin{tabular}{|l|l|l|l|l|}
\hline Plastic type & $\begin{array}{l}\text { Density } \\
\left(\mathrm{g} / \mathrm{cm}^{3}\right)\end{array}$ & $\begin{array}{l}\text { Specific heat } \\
(\mathrm{J} / \mathrm{kg} \cdot \mathrm{K})\end{array}$ & $\begin{array}{l}\text { Thermal conductivity } \\
(\mathrm{W} / \mathrm{m} . \mathrm{K})\end{array}$ & $\begin{array}{l}\text { Melting point } \\
\left({ }^{\circ} \mathrm{C}\right)\end{array}$ \\
\hline HDPE & 0.95 & $2000-2500$ & $0.44-0.48$ & $140-160$ \\
\hline PP & 0.90 & $1500-2000$ & $0.19-0.22$ & $160-180$ \\
\hline
\end{tabular}

The work has conducted at Chemical Lab in Materials Engineering Department, Mustansiriyah University. Several devices and instruments have been used like, oven, thermometer, weight scale and molds. Some tools and auxiliaries have been used as well. The majority of WPC researches suggested considering an amount of wood less than that of plastic to ensure sufficient bonding between the two components, thus the current study assumed a wood content not exceeded $30 \%$ of the total weight. The wood was oven dried at $80{ }^{\circ} \mathrm{C}$ for 2 hours before processing to remove the moisture content (so the final moisture content will not exceed $5 \%$ ). However, WPC specimens prepared in the current study with their mixing ratios are shown in Table 2.

Table 2. Mixing ratios of WPC specimens used in the study

\begin{tabular}{|l|l|l|}
\hline WPC type & Mixing ratio (\% wt) & No. of specimens \\
\hline HDPE & 100 & 2 \\
HDPE-PW & $90-10,80-20,70-30$ & 6 \\
\hline PP & 100 & 2 \\
PP-PW & $90-10,80-20,70-30$ & 6 \\
\hline
\end{tabular}

The desired quantities for each specimen components have weighted and combined in well mixing procedure, where two stages have proposed to ensure homogenous product as much as possible. In the first stage, some of the wood flour has mixed with the plastic grains in a bowl and then pour the mixture into a sheet of parchment paper to insert it easily to the oven for a period of time till the melting point. After that, the second stage of mixing is beginning by spreading the rest of the wood flour into the melted plastic and rolling it carefully. The oven used in the study is assigned for polymer melt-works which has the brand Jrad, with Italian 
thermostat operates up to $250{ }^{\circ} \mathrm{C}$. The period that the plastic grains spent in the oven to get melting, starting from room temperature, was ranged between 20-30 minutes at a constant rate of heat $\left(10^{\circ} \mathrm{C} / \mathrm{min}\right)$. After that, the molten plastic-wood paste has ejected from the oven and inserted into the mold. The paste of wood-plastic should be pressed in the mold using a cap which holds a weight of $2 \mathrm{~kg}$ and for a period of 10 minutes. The advantage of pressing is to strengthen the produced specimen during heat transfer process in the product to ensure sufficient WPC formation. Parchment paper or aluminum foil could be used in the base of the mold to extract the specimens easily. Finally, the specimens in the mold should be exposed to the still air for a period of 5 minutes for cooling. Measurements of thermal conductivity require specimens that have circular shapes of $42 \mathrm{~mm}$ diameter, as shown in Figure 1.

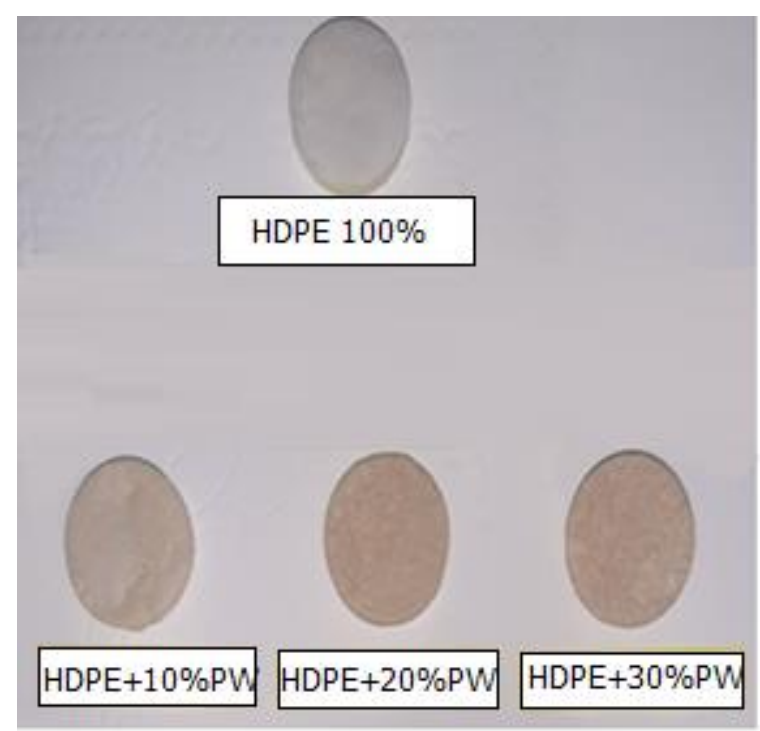

a. HDPE-Wood

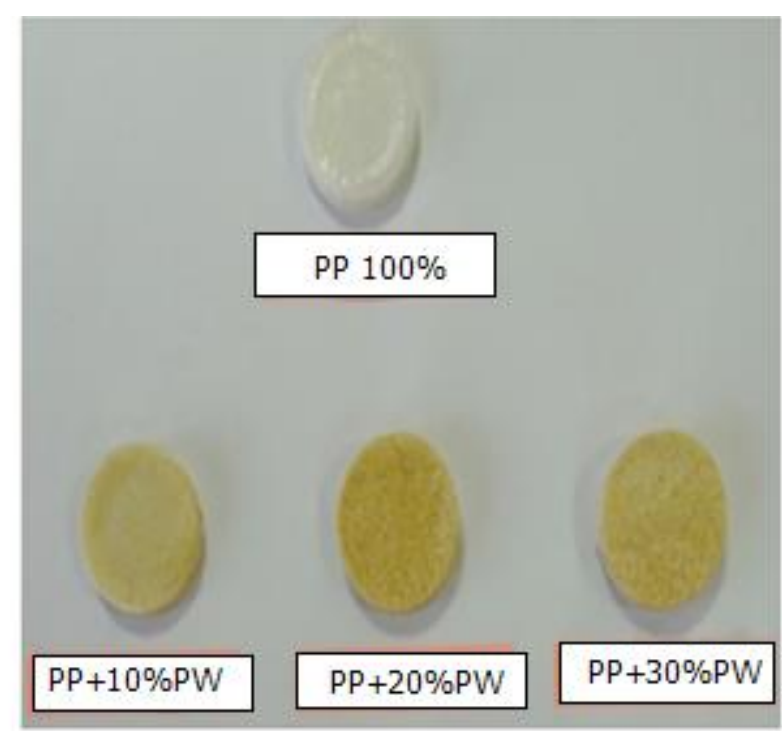

b. PP-Wood

Figure 1. Final shapes of WPC specimens

\section{MEASUREMENTS}

The coefficient of thermal conductivity is the most important property of any material which indicates whether it is an insulator or not. Material with relatively low thermal conductivity, less than $0.2 \mathrm{~W} / \mathrm{m} . \mathrm{K}$, consider as a good thermal insulator (Tawfeeq, 2017). The measurements of thermal conductivity for the specimens have conducted at the laboratory of Materials Research Department in Ministry of Science and Technology (MOST) according to ASTM C518 - 04, using Lee's disc apparatus, as shown in Figure 2. The device consists of a chamber 
and a reader. The chamber has an electric heater, and there is a group of discs where the specimen should be placed between the hot and cold discs. The chamber has sufficient thermal insulation. The electric circuit was switched on until the equilibrium condition is reached. The reader recorded the temperatures across the specimen using sensors connected to a thermometer. The recorded values have compensated in a special equation approved for this device.

The measurements of melting temperatures have conducted at Chemical Lab in Materials Engineering Department, where the specimens have been melted in the oven. Digital thermometer Doradus GM-1312 with sensors of Type-K has used to measure the melting points. The thermal sensor has inserted in the wood-plastic paste in the closed oven to measure its temperature till reaching the melting point, as shown in Figure 3. This test should be repeated several times in order to obtain accurate values of melting point and exact time required to reach it. Thermal stability of the polymer is defined as the ability of the polymeric material to resist the action of heat at high temperatures, which is important to maintain its physical properties. The mass loss, as a function of temperature, is monitored and thermal stability of the material is evaluated by the percentage loss in its initial mass. Note that mass loss of thermoplastics is negligible in temperatures below $370{ }^{\circ} \mathrm{C}$ (Alireza, 2010). Since the maximum surface temperatures for thermal insulating panels used for residential applications are usually less than $80{ }^{\circ} \mathrm{C}$, thus there is no possibility to lose mass of polymer in this range. However, the measurement of thermal stability of WPC is important due to the absence of wood in the composite, where there is an amount of evaporation for some wood components. This test has occurred to know the amount of mass loss during the manufacturing of the WPC material by applying temperature not exceeded $200{ }^{\circ} \mathrm{C}$, which is a bit over the melting point of each polymer. Hence, the mass loss is too small, which is also mentioned by Klaudia et al., 2010 \& Nourbakhsh et al., 2010. Initial weight of WPC specimen before melting and final weight after melting should be measured to calculate the percentage loss in the mass of WPC. 


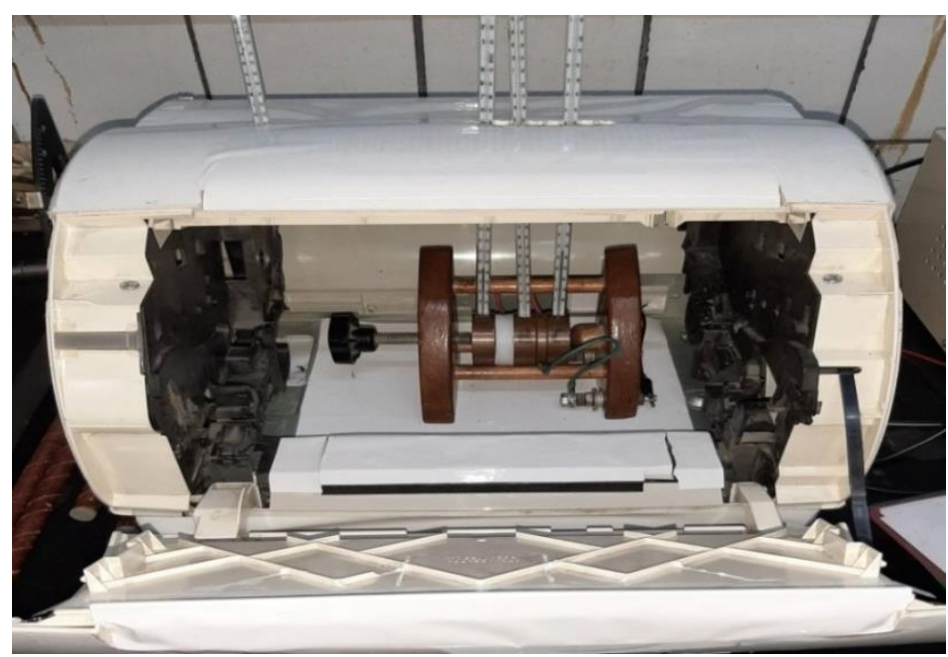

Figure 2. Specimen is placed in the apparatus between hot and cold discs

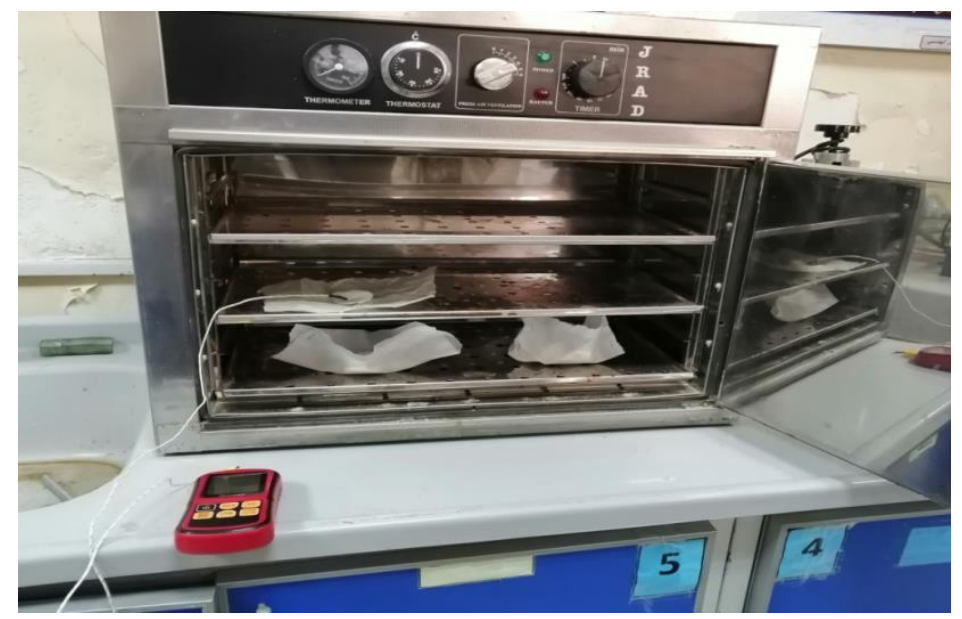

Figure 3. Measuring the melting point of the specimen

\section{RESULTS AND DISCUSSIONS}

Evaluating the thermal performance of WPC insulating panels depends mainly on the values of thermal conductivity as an essential parameter in the thermal analysis. Other parameters like melting point and thermal stability have investigated as well.

In general, the increasing in wood content leads to a reduction in k-value for WPC material because k-value of wood is less than that of polymer, thus the overall k-value of the composite tends to decrease. This decreasing was linear, as shown in Figure 4 ( $a$ and b). For HDPE-wood composites, it is noticed that there is a significant reduction in k-value when pine wood is used, due to the low $\mathrm{k}$-value for pine wood $(\mathrm{k}=0.12 \mathrm{~W} / \mathrm{m} . \mathrm{k})$. The reduction in $\mathrm{k}$-value of HDPE-wood 
composite for every $10 \%$ addition of wood was about $6-10 \%$. This amount of increasing is going to be double when there is $20 \%$ addition of wood, or triple when there is $30 \%$ addition of wood. For PP-wood composites, the reduction in the k-value by the increasing of wood content was small (4-6\%) due to the fact that k-value of pure PP raw material is basically low $(\mathrm{k}=0.22$ $\mathrm{W} / \mathrm{m} . \mathrm{k})$ compared to that of HDPE ( $\mathrm{k}=0.48 \mathrm{~W} / \mathrm{m} . \mathrm{k})$. Hence, the addition of wood to PP has less reduction in k-value. So, it is concluded that the technique of WPC is useful with plastics that have relatively high k-values (more than $0.3 \mathrm{~W} / \mathrm{m} . \mathrm{k}$ ) such as; HDPE, LDPE and PA in order to get clear benefits of wood addition, thus reasonable results. Effect of wood content on $\mathrm{K}$-value of WPCs was investigated also by some studies with respect to their conditions. Table 3 shows a comparison between the results for species tested in the mentioned studies with the current study, where the studies referred to the fact of reduction in the value of thermal conductivity of WPC due to the increasing of wood content.

Table 3. Effect of wood content on k-values for many studies

\begin{tabular}{|l|l|l|l|l|}
\hline Study & João et al., 2017 & Karim, et al., 2013 & Prisco, 2014 & Current study \\
\hline Type of plastic used & PP & LDPE & HDPE & $\begin{array}{l}\text { HDPE } \\
\text { \% reduction in k- } \\
\text { value by increasing } \\
\text { the wood 10\% }\end{array}$ \\
\hline
\end{tabular}




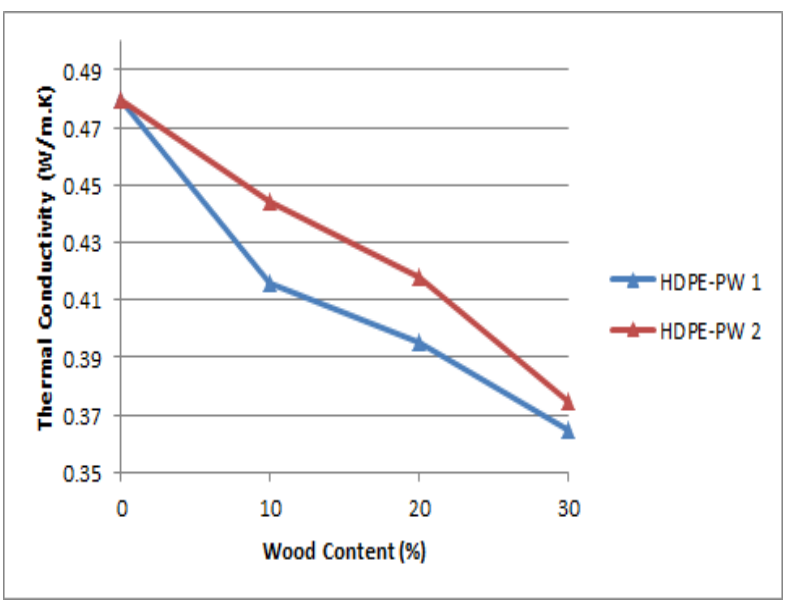

a. HDPE-PW

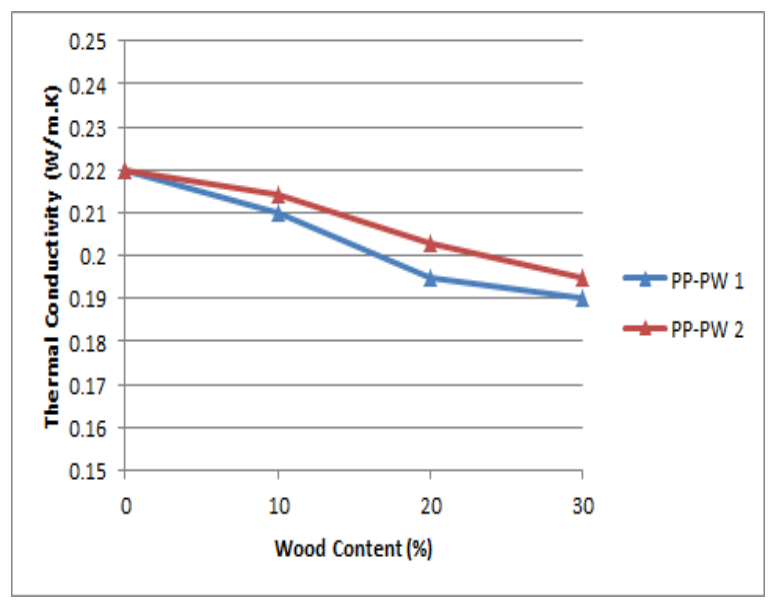

b. PP-PW

Figure 4. K-values for studied WPCs

Mass loss in HDPE-PW and PP-PW composites up to $200{ }^{\circ} \mathrm{C}$ has been measured for different wood contents $(10,20$ or $30 \%)$, as shown in Tables 4 and 5. The increase of wood content in the composition of WPC will increase the mass loss of the composite material (WPC) due to the evaporation of the water in the cellulosic cells of the wood, as well as the partially degradation of these cells. The loss in mass starts approximately at a temperature above $150^{\circ}$ $\mathrm{C}$, as shown in Figure 5 ( $\mathrm{a}$ and $\mathrm{b}$ ). Generally, the mass loss is relatively small and does not exceed $(10 \%)$. So, the wood could be used with plastics that have low melting points, or below the degradation temperature of wood (such as HDPE, LDPE, PP, PVDF and PA) to ensure less mass loss and more thermal stability. The problem of thermal stability would be more effective if plastics that have high melting points (such as PVC, PS and PET) were used. However this problem can be treated by adding some stabilizers and coupling agents. However, the effect of wood content on the thermal stability of WPCs has compared to some studies, as shown in Table 6. These studies referred to the fact of increasing the mass loss of WPC due to the increasing of wood content. However, the comparison gives a good convergence between these results. 
Table 4. Effect of wood content on mass loss of PP-PW composites

\begin{tabular}{|l|l|l|l|l|}
\hline \%Wood & Initial mass $(\mathrm{g})$ & Final mass $(\mathrm{g})$ & Mass loss \% & Mass remain \% \\
\hline 0 & 10 & 9.70 & 3.0 & 97.0 \\
\hline 10 & 10 & 9.32 & 6.8 & 93.2 \\
\hline 20 & 10 & 9.14 & 8.6 & 91.4 \\
\hline 30 & 10 & 9.01 & 9.9 & 90.1 \\
\hline
\end{tabular}

Table 5. Effect of wood content on mass loss of PP-PW composites

\begin{tabular}{|l|l|l|l|l|}
\hline \%Wood & Initial mass $(\mathrm{g})$ & Final mass $(\mathrm{g})$ & Mass loss \% & Mass remain \% \\
\hline 0 & 10 & 9.80 & 2.0 & 98.0 \\
\hline 10 & 10 & 9.51 & 4.9 & 95.1 \\
\hline 20 & 10 & 9.33 & 6.7 & 93.3 \\
\hline 30 & 10 & 9.24 & 7.6 & 92.4 \\
\hline
\end{tabular}

Table 6. Effect of wood content on the thermal stability for many studies

\begin{tabular}{|l|l|l|l|l|l|}
\hline Study & $\begin{array}{l}\text { Alireza, } \\
2010\end{array}$ & $\begin{array}{l}\text { Rafel et } \\
\text { al., 2015 }\end{array}$ & $\begin{array}{l}\text { Alperen, et } \\
\text { al., 2017 }\end{array}$ & $\begin{array}{l}\text { Yong et } \\
\text { al., 2019 }\end{array}$ & $\begin{array}{l}\text { Current } \\
\text { study }\end{array}$ \\
\hline Type of plastic & HDPE & PP & PP+zeolite & HDPE & $\begin{array}{l}\text { HDPE } \\
\text { PP }\end{array}$ \\
\hline $\begin{array}{l}\text { \% increasing in mass loss by } \\
\text { increasing the wood } 10 \%\end{array}$ & $3 \%$ & $2 \%$ & $1 \%$ & $2 \%$ & $2-4 \%$ \\
\hline
\end{tabular}




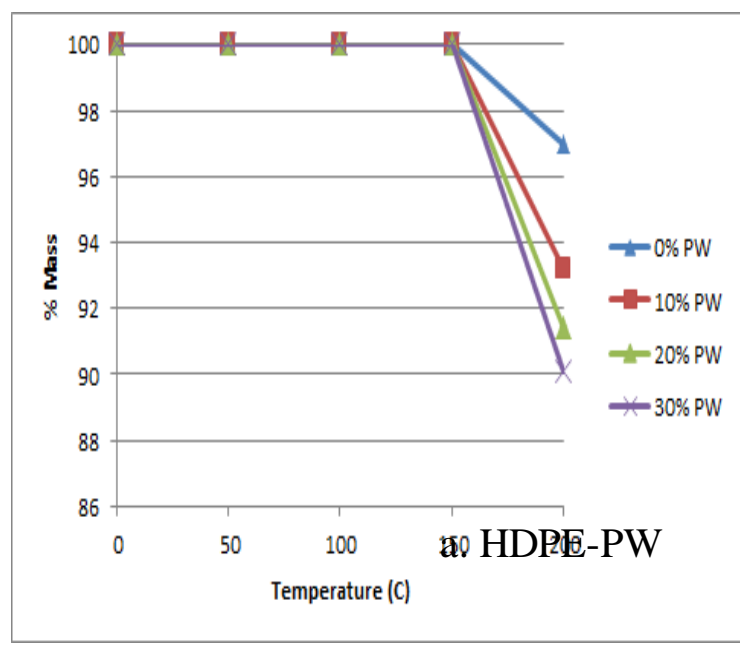

a. HDPE-PW

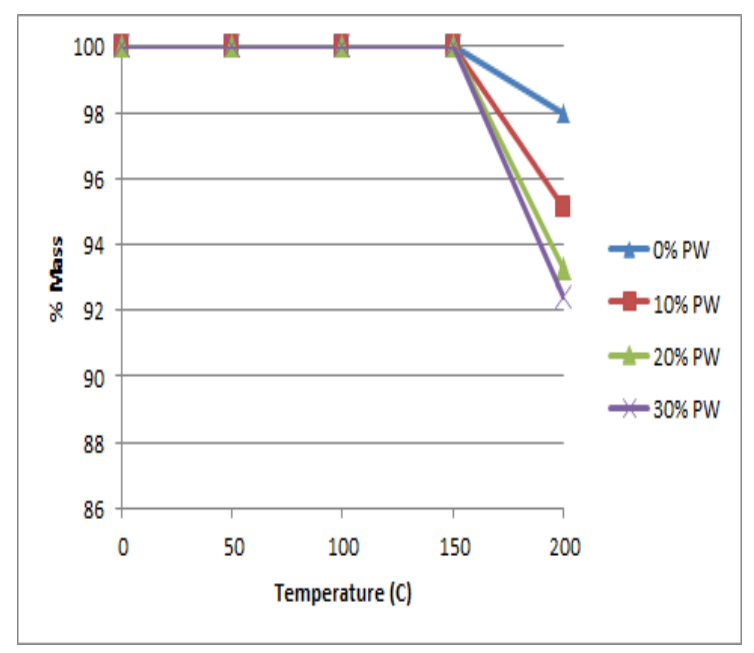

b. PP-PW

Figure 5. Mass loss for studied WPCs

The melting point (Tm) of HDPE-PW and PP-PW has measured for different wood contents $(10,20$ or $30 \%)$, as shown in Tables 7 and 8 . It is clear that pure HDPE without wood has taken $(20 \mathrm{~min})$ to melt starting from room temperature $\left(20^{\circ} \mathrm{C}\right)$ and reached melting point at $\left(151.5^{\circ} \mathrm{C}\right)$. On the other hand, pure PP without wood has taken $(26 \mathrm{~min})$ to melt starting from room temperature and reached melting point at $\left(163.8^{\circ} \mathrm{C}\right)$. When wood has been added to the plastics, melting points had increased as well as the time required for melting. The melting point increased due to thermal insulation performance of wood, which restricted the movement of heat conduction. The addition of $10 \%$ wood, to the composite, leads to increase the melting point by $2-3^{\circ} \mathrm{C}$ for both HDPE and PP. This ratio is closed to that concluded by Alireza, 2010 \& Yong et al., 2019, where the addition of $10 \%$ wood, to the composite, leads to increase the melting point by $1-2^{\circ} \mathrm{C}$.

Table 7. Effect of wood content on melting point of HDPE-PW composites

\begin{tabular}{|l|l|l|}
\hline \% Wood & Melting point $\left({ }^{\circ} \mathrm{C}\right)$ & Time for melting (min) \\
\hline 0 & 151.5 & 20 \\
\hline 10 & 153.8 & 22 \\
\hline 20 & 157.1 & 25 \\
\hline 30 & 159.2 & 26 \\
\hline
\end{tabular}


Table 8. Effect of wood content on melting point of PP-PW composites

\begin{tabular}{|l|l|l|}
\hline$\%$ Wood & Melting point $\left({ }^{\circ} \mathrm{C}\right)$ & Time for melting (min) \\
\hline 0 & 163.8 & 26 \\
\hline 10 & 166.5 & 28 \\
\hline 20 & 169.1 & 29 \\
\hline 30 & 171.4 & 31 \\
\hline
\end{tabular}

The melting point $(\mathrm{Tm})$ gives an indication of many properties related polymeric materials and it may also have a direct effect on the values of many other thermal properties such as the thermal expansion coefficient $(\alpha)$. For a symmetrical polymer which has a rubbery state at room temperature, a suitable correlation is given by (Krevelen et al., 2009):

$\alpha=\frac{0.328}{T m}$

For the wood, it can be assumed that the thermal expansion coefficient is constant at a certain value of $\left(0.5 \times 10^{-4} \mathrm{~K}^{-1}\right)$ since it is too small. However, a simple mixing rule is used to calculate the properties of composite materials depending of the content ratio $(\varphi)$, which is given by:

$\alpha_{\text {composite }}=\alpha_{\mathrm{p}} \varphi_{\mathrm{p}}+\alpha_{\mathrm{w}} \varphi_{\mathrm{w}}$

Where $\left(\alpha_{\mathrm{p}}, \alpha_{\mathrm{w}}\right)$ is thermal expansion coefficient of polymer and wood, respectively.

Accordingly, the results of thermal expansion coefficient $(\alpha)$ of HDPE-PW and PP-PW for different wood contents $(10,20$ or $30 \%)$, are shown in Tables 9 and 10. When wood has been added to the polymer, melting point ( $\mathrm{Tm}$ ) has increased. The increasing in the melting point (Tm) leads to decrease the thermal expansion coefficient $(\alpha)$ of the polymeric material because there is an inverse relationship between these properties. The results show that the addition of $10 \%$ wood, to the composite, leads to reduce $(\alpha)$ about $8-12 \%$. The addition of wood to the composite means less expansion since wood is more rigid than plastic. As a result, when the composite's thermal expansion coefficient has decreased, the material became more rigid. In a mechanical point of view, thermal expansion coefficient of composite is decreased due to the influence of reinforced fillers (wood). 
Table (9) Effect of wood content on thermal expansion of HDPE-PW composites

\begin{tabular}{|l|l|l|l|}
\hline$\%$ Wood & Melting point $(\mathrm{K})$ & $\alpha$ of polymer $\left(\mathrm{K}^{-1}\right)$ & $\alpha$ of WPC $\left(\mathrm{K}^{-1}\right)$ \\
\hline 0 & 424.5 & $7.73 \times 10^{-4}$ & $7.73 \times 10^{-4}$ \\
\hline 10 & 426.8 & $7.69 \times 10^{-4}$ & $6.97 \times 10^{-4}$ \\
\hline 20 & 430.1 & $7.63 \times 10^{-4}$ & $6.20 \times 10^{-4}$ \\
\hline 30 & 432.2 & $7.60 \times 10^{-4}$ & $5.47 \times 10^{-4}$ \\
\hline
\end{tabular}

Table (10) Effect of wood content on thermal expansion of PP-PW composites

\begin{tabular}{|l|l|l|l|}
\hline$\%$ Wood & Melting point $(\mathrm{K})$ & $\alpha$ of polymer $\left(\mathrm{K}^{-1}\right)$ & $\alpha$ of WPC $\left(\mathrm{K}^{-1}\right)$ \\
\hline 0 & 436.8 & $7.51 \times 10^{-4}$ & $7.51 \times 10^{-4}$ \\
\hline 10 & 439.5 & $7.46 \times 10^{-4}$ & $6.76 \times 10^{-4}$ \\
\hline 20 & 442.1 & $7.42 \times 10^{-4}$ & $6.04 \times 10^{-4}$ \\
\hline 30 & 444.4 & $7.38 \times 10^{-4}$ & $5.32 \times 10^{-4}$ \\
\hline
\end{tabular}

\section{CONCLUSIONS}

Wood plastic composites (WPCs) that manufactured from waste pine wood and recycled HDPE and PP plastics have possessed some advantages since they are renewable and environmentally fried, and present some desired thermo-physical properties. However, some specific points could be concluded from the current study as following:

- The technique of WPC is useful for plastics of high k-values $(>0.3 \mathrm{~W} / \mathrm{m} . \mathrm{k})$ such as; HDPE and PA in order to get clear benefits of wood addition and reasonable results.

- The increasing in wood content leads to a decrease in k-value for WPC by $4-10 \%$ for each $10 \%$ addition of wood.

- The increasing of the wood content increases the melting point of WPC due to thermal insulating performance of wood, and decreases thermal expansion because the material becomes more rigid.

- The increase of wood content in the composition of WPC will increase the mass loss of the composite material (WPC). 


\section{ACKNOWLEDGMENTS}

Authors are grateful to the support given by College of Engineering, Mustansiriyah University for academically aid and facilities.

\section{REFERENCES}

Saleem M., Nawaf I., Alshamrani S., Abdulaziz B., "Fundamental investigation of solid waste generation and disposal behavior in higher education institute of kingdom of Saudi Arabia”, Indoor and Built Environment, Vol. 28, issue 7, pp. 927-937, 2019.

DOI: https://doi.org/10.1177/1420326X18804853,

Tabarsa T., Khanjanzadeh H., Pirayesh H., "Manufacturing of wood-plastic composite from completely recycled materials", Key Engineering Materials, Vols. 471-472, Pages 62-66, 2011

Adam T., Vikram Y., Karl R., David H., "Wood plastic composites - a primer", Washington State University, PB 1779, 2010

Andre S., "Wood plastic composites (WPCs) as an alternative to solid lumber", Thesis, University of British Columbia, 2011

João B., Carlos M., Fernando C., Raul F., "Influence of different thermoplastic polymer/wood ratios on the mechanical and thermal properties of composite materials", Procedia Engineering, 200, 480-486, 2017

Wolcott M., Englund K., "A technology review of wood plastic composites", 33rd International Particleboard/Composite Materials Symposium, Washington State University, Pages 103-110, 1999

John Z., Qinglin W., Ioan I., "Surface and interfacial characterization of wood-PVC composites: Thermal and dynamic mechanical properties", Wood and Fiber Science, 36(4), Pages 500-510, 2004

Alireza Kaboorani, "Effects of formulation design on thermal properties of wood/thermoplastic composites", Journal of Composite Materials, Vol. 44, No. 18, Pages 2205 2215,2010

Song G., Qiu-yi L., Yi-wen Z., "Experimental research on the thermal insulation and flame 
retardancy performance of WPC wallboard made of paper-aluminum-plastics wastes", Applied Mechanics and Materials, Volumes 34-35, Pages 1676-1680, 2010

Diene N., Laurent M., Sandrine M., Loic V., Adams T., Jean-Luc G., "Thermal and mechanical properties of polypropylene/wood-flour composites", Journal of Applied Polymer Science, Vol. 119, Pages 3321-3328, 2011

Thanate R., Natchayapa T., Chatree H., "Mechanical and thermal properties of oil palm wood sawdust reinforced post-consumer polyethylene composites", ScienceAsia, 38, Pages 289-294, 2012

Yiqun F., Qingwen W., Xiaoyan B., Weihong W., Paul A., "Thermal and burning properties of wood flour poly (vinyl chloride) composite", J Therm Anal Calorim, 109:1577-1585, 2012

Karim B., Bernard R., Denis R., "Effect of temperature on the thermal conductivity of woodplastic composites", Polymers \& Polymer Composites, Vol. 21, No. 7, 2013

Prisco U., "Thermal conductivity of flat-pressed wood plastic composites at different temperatures and filler content", Sci Eng Compos Mater, 21(2), Pages 197-204, 2014

Mazzanti V., Mollica F., El Kissi N., "Rheological and thermal properties of PP-based WPC", Times of polymers and composites, AIP Conference, Pages 274-277, 2014

Hossain M., Shoumya N., Islam M., "Effect of types of wood on the thermal conductivities of wood saw dust particle reinforced composites", 10th International Conference on Mechanical Engineering, ICME 2013, Procedia Engineering, 90, Pages 46 - 51, 2014

Rafel R., Josep P., José M., Jordi G., Francesc X., Gerard A., Pere M., "Orange wood fiber reinforced polypropylene composites: Thermal properties", Bioresources, 10(12), Pages 21562166,2015

Patrick Z., Elke M., Andre G., Torsten T., Antje L., "Synthesis of polyamide 6/11 copolymers and their use as matrix polymer in wood-plastic composites", Journal of Applied Polymer Science, 44155, Wiley, 2016

Alperen K., Turker G., Seyyed H., Nadir A., "Physical, mechanical and thermal properties of wood/zeolite/plastic hybrid composites", Maderas, Ciencia y tecnología, 19(3): 339 - 348, 2017 
Chung M., Park J., "An experimental study on the thermal performance of phase-change material and wood-plastic composites for building roofs", MDPI, Energies, 10 (195), 2017

Shirley S., Leigh M., Tim G., Adrian K., "Properties of nylon-6-based composite reinforced with coconut shell particles and empty fruit bunch fibres", Plastics, Rubber and Composites, T\&F, VOL. 47, NO. 2, Pages 77-86, 2018

Yong G., Shiliu Z., Yuxia C., Dagang L, "Thermal properties of wood-plastic composites with different compositions", Materials, MDPI, 12:881, 2019

Xingli Z., Jinglan Z., Ruihong W., "Thermal and mechanical behavior of wood plastic composites by addition of graphene nanoplatelets", MDPI, Polymers, 11, 1365, 2019

Henry M., A. Besnard, W. Asante, J. Eshun, S. Adu-Bredu, R. Valentini, M. Bernoux, L. Saint-Andre, "Wood density, phytomass variations within and among trees, and allometric equations in a tropical rainforest of Africa", Forest Ecology and Management, 260, Pages $1375-1388,2010$

Glass S., Zalinka L., "The wood handbook: Wood as an engineering material, Chapter 4: Moisture relations and physical properties of wood", General Technical Report, USA, 2010

Poletto M., Dettenborn J., Pistor V., Zeni M., Zattera A., "Materials produced from plant biomass, Part I: Evaluation of thermal stability and pyrolysis of wood", Materials Research, 13 (3), Pages 375-379, 2010

Poletto M., "Thermogravimetric analysis and kinetic study of pine wood pyrolysis", Brazilian Journal of Wood Science, 7(2), Pages 111-118, 2016

Polymer Database, accessed on 19/11/2020, http://polymerdatabase.com

Tawfeeq W. Salih, "Insulation materials", Bachelor Notes, Mustansiriyah University, 2017

Klaudia K., Kinga P., "Thermal decomposition of polymer nanocomposites with functionalized nanoparticles", Polymer Composites with Functionalized Nanoparticles, Synthesis, Properties, and Applications, Micro and Nano Technologies, Pages 405-435, 2019

Nourbakhsh A., A. Ashori, H. Tabari, F. Rezaei, "Mechanical and thermo-chemical properties of wood-flour/polypropylene blends", Polym. Bull., 65, Pages 691-700, 2010 Krevelen D., Nijenhuis K., "Properties of polymers", 4th edition, Elsevier, 2009 